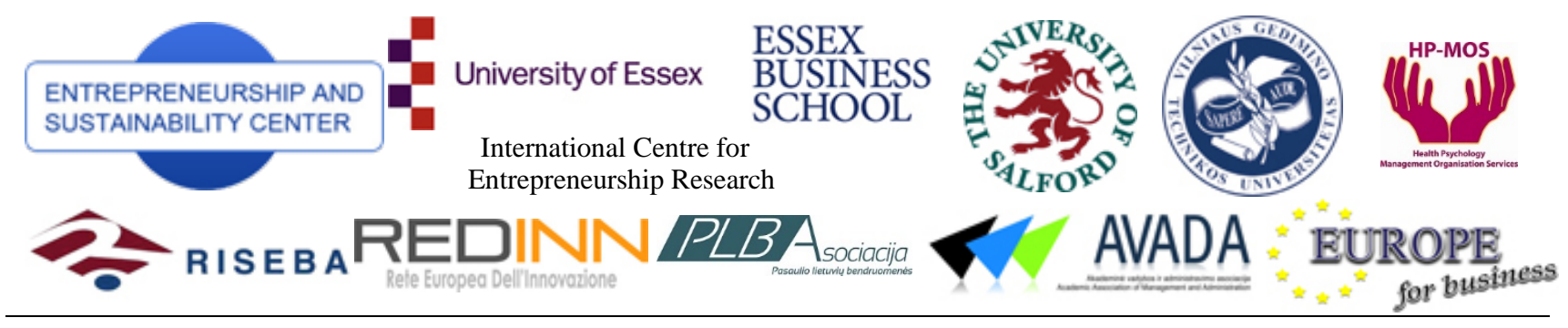

ENTREPRENEURSHIP AND SUSTAINABILITY ISSUES

ISSN 2345-0282 (online) http://jssidoi.org/jesi/aims-and-scope-of-research/

\title{
TOWARDS INNOVATIVE DISTRICT ENERGY MANAGEMENT: A CASE STUDY WITH STOCHASTIC RENEWABLE GENERATORS
}

\author{
Stefano Barberis ${ }^{1}$, Francesco Roncallo ${ }^{2}$, Alberto Traverso ${ }^{3}$ \\ Department of Mechanical Engineering, TPG, University of Genoa, Via Montallegro 1, 16145 Genoa, Italy \\ E-mails: ${ }^{1}$ Stefano.barberis@edu.unige.it, ${ }^{2}$ Francesco.roncallo@edu.unige.it, ${ }^{3}$ alberto.traverso@unige.it
}

Received 10 September 2016; accepted 22 November 2016

\begin{abstract}
The conversion of ocean wave power into sustainable electrical power represents a major opportunity to Nations endowed with such a kind of resource. At the present time the most of the technological innovations aiming at converting such resources are at early stage of development, with only a handful of devices close to be at the commercial demonstration stage. The Seaspoon device, thought as a large energy harvester, catches the kinetic energy of ocean waves with promising conversion efficiency, and robust technology, according to specific "wave-motion climate”. University of Genoa developed and patented a prototype to be deployed in medium average energy content seas (i.e. Mediterranean or Eastern Asia seas). This paper presents the installation phases of the first real scale prototype installed in the gulf of Genova and the monitoring of its performances. A brief description of the Seaspoon WEC is presented together with the monitoring equipment and procedures.In this research a thermoeconomic analysis of its integration in a real polygenerative district is also investigated. The impact of such this kind of stochastic renewable generator in the Savona Campus Smart Polygeneration Microgrid (SPM) is evaluated. The SPM plant is made up by (i) two auxiliary boilers (500kWth each), (ii) four micro gas turbines (30kWe, 2x65kWe and 100kWe), (iii) an internal combustion engine fed by natural gas (20kWe), (iv) an absorption chiller (100 kWf) and (v) PV panels for a total power installed of $100 \mathrm{kWe}$. Generators are "distributed" around the campus and they are coupled to electrical and thermal storages. Since the system is constituted by co-generative prime movers it can supply both electrical and thermal energy of the campus and the integration of storage is really important in order to follow both the requests, pursuing the best management strategy.

The analysis of this smart-grid is performed exploiting a software developed by the Author's research group, which allows for the thermo-economic optimization of poly-generative energy systems. A model of the real plant was built and it was implemented in the software. The off-design curves of the real devices installed in the campus were used in order to increase the reliability of the simulation results. The grid was simulated considering the time dependent nature of the demands throughout the whole year. The model was used to simulate the smart grid behavior during the whole year, and find the best operational strategy. A time-dependent thermo-economic hierarchical approach has been used, considering the time-dependent electrical, thermal and cooling load demands during the year as problem constraints. The results are presented and discussed in depth and show the strong interaction between fossil and renewable resources, particularly the impact of unpredictable and randomized generators like the WECs ones. A dedicated model of the Seaspoon was implemented and exploited in the code.
\end{abstract}

Keywords: wave energy converter, smart grid, energy storage, thermoeconomics, polygeneration 
Reference to this paper should be made as follows: S. Barberis, F. Roncallo, A. Traverso. 2017. Towards innovative district energy management: a case study with stochastic renewable generators, Entrepreneurship and Sustainability Issues, Entrepreneurship and Sustainability Issues 4(3): 294-309. http://dx.doi.org/10.9770/jesi.2017.4.3S(5)

JEL Classifications: Q20, Q42

Additional disciplines: energetics and thermoenergetics, environmental engineering

\section{Introduction}

The integration of renewable and other efficient distributed power generation sources into existing and future unified electricity systems represents an enormous technological challenge which can be overcome particularly thanks to energy storage and the management of power demand and production by the exploitation of Information and Communications Technology. All these technologies are the fundamentals of Smart Grids and they are the crucial research topic in Europe for a new Energetic revolution (Barstow et al. 2003).

Distributed generation (DG) will play a key role in this novel scenario (Falnes et al. 2007) enabling new roles of citizens as prosumers instead of simple consumer of energy (Olkkonen et al. 2016) also requiring specific social (Tvaronavičienė et al. 2012) and business models (Izvercianu et al. 2014). It covers a broad range of technologies, including many renewable technologies supplying small scale power at sites close to users. Highly efficient combined heat and power (CHP) plants, back-up and peak load systems are providing increasing capacity. Together with renewable energy, these technologies offer new market opportunities and enhanced industrial competitiveness.

The ocean waves are an important renewable energy resource that, if extensively exploited, may contribute significantly to the electrical energy supply of countries with coasts facing the ocean (Barstow et al. 2003). A wide variety of technologies has been proposed, studied, and in some cases tested at full size in real ocean conditions (Izvercianu et al. 2014; Drew et al. 2009; FalcãoA.F.de O et al. 2010; Lopez et al. 2013). The mechanical process of energy absorption from the waves requires a moving interface, involving (i) a partly or totally submerged moving body and/or (ii) a moving air-water interface subject to a time-varying pressure. This kind of generators can be exploited in distributed generation facilities particularly for smart grids and district energy located nearby the shores where the sea has a considerable wave energy potential. The production of WECs is strongly aleatory, even if it is a little bit more predictable than wind power. Due to strongly randomized production, it is important to evaluate the interaction of this kind of generators with the other equipment (generators and storage) installed in the local energy district in order to maximize the exploitation of WECs' production.

The management of distributed generation facilities, the demand-side management, the design of the energy district is a complex multiobjective optimization process that could be analysed through a thermoeconomic approach. Thermo-economic analysis (Verda et al. 2001) is a well-known method to approach energy systems, in order to develop efficient and profitable real time controllers and to identify the best size for the different installed devices. Energy storage systems can help in successfully meeting the district energy demand, such as building heating and cooling applications, and they are able to solve the problems of not dispatchable renewable energy sources in the electrical market.

The purpose of this paper is to evaluate the impact of an original patented WEC named SeaSpoon, developed by the researchers of the Thermochemical Power Group, in the management of a real polygenerative energy district installed at the University of Genoa campus located in Savona (Bracco et al. 2013). A one-year analysis is carried out with one hour time intervals, taking into proper account the time-dependent nature of energy demands, RES generation and investigating the best operational strategy for the devices. A thermoeconomic model of the SeaSpoon was developed in the original software W-ECoMP (Web-based Economic Cogeneration Modular Program) (Barberis et al. 2016) thanks to the optimization process was performed, which aims to investigate the best management strategy of the devices installed in polygenerative energy districts in order to satisfy the load energy demands and make eventual new equipment installations profitable. 


\section{Savona Campus Smart Polygeneration Microgrid}

In the previously introduced scenario, one of the most innovative European demonstrator is the Smart Polygeneration Microgrid (SPM) (Fig.1), installed in the University of Genoa campus, located in Savona (Italy), and built with both the contribution of the Italian Ministry of Education, University and Research MIUR and the European Project FP7 RESILIENT. The SPM installed in Savona includes several commercial CHP units, traditional prime movers and renewable generators, as it follows:

- A cogenerative micro gas turbine (mGT) Turbec T100, $100 \mathrm{kWe}, 165 \mathrm{kWth}$ and a cogenerative internal combustion engine (ICE) TANDEM T20, $20 \mathrm{kWe}, 44 \mathrm{kWth}$; (these two CHP units are included in the Innovative Energy System laboratory managed by TPG)

- A cogenerative micro gas turbine (mGT) Capstone C30, 30 kWe, 49 kWth;

- Two cogenerative micro gas turbines (mGT) Capstone C65, each rated 65 kWe, 112 kWth;

- A photovoltaic roof of $400 \mathrm{~m} 2$, corresponding to a peak power of about $77 \mathrm{kWe}$;

- Three CSP dish Stirling units, each rated $1 \mathrm{kWe}, 3 \mathrm{kWth}$;

- Two conventional gas natural boilers, each rated $500 \mathrm{kWth}$;

- Two absorption chillers, LWM-W003, each rated $100 \mathrm{kWth}$;

- Two storage tanks for hot water, for a total volume of 10,000 l;

- A storage tank for cold water, volume of 3,000 l;

- A FIAMM SoNick electrical energy storage, capacity of $470 \mathrm{Ah}$ and nominal voltage of $300 \mathrm{~V}$. 

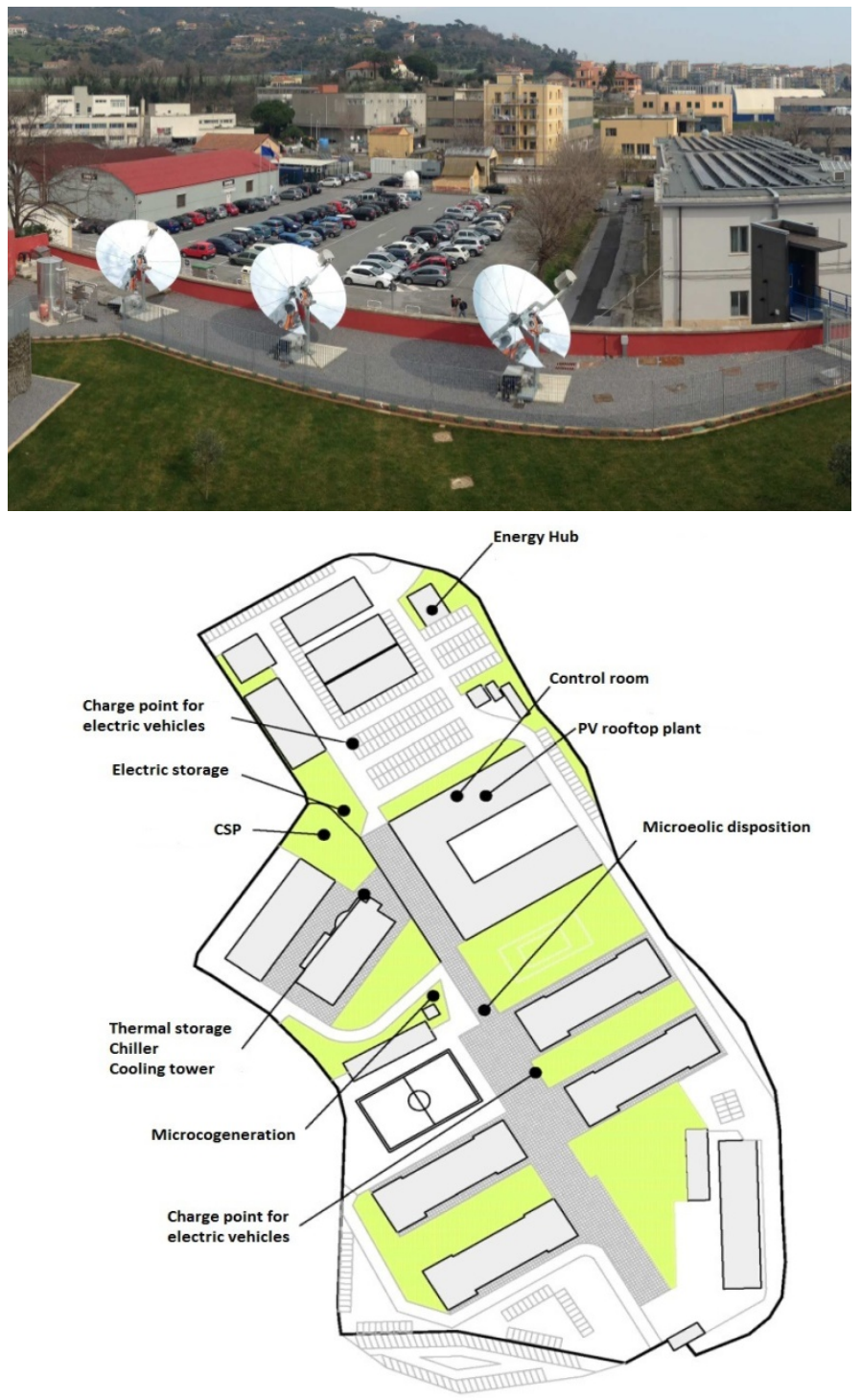

Fig.1. University of Genoa campus located in Savona (above) - SPM overview (below).

The SPM is connected to the National electrical grid in a single point. The CSP dish Stirling units (Fig.1 above) contribution to the grid will not be ever considered in the present analysis, as the thermal and electrical production of these units is negligible.

\section{The SeaSpoon Wave Energy Converter}

The development of an innovative wave energy converter designed to exploit the Mediterranean Sea wave energy potential started in 2010 at the Thermochemical Power Group. A first design and layout was patented in 2011 and the concept originates from merging the best technologies of existing Wave Energy Converter (WEC) devices with up to date wind energy turbines. 


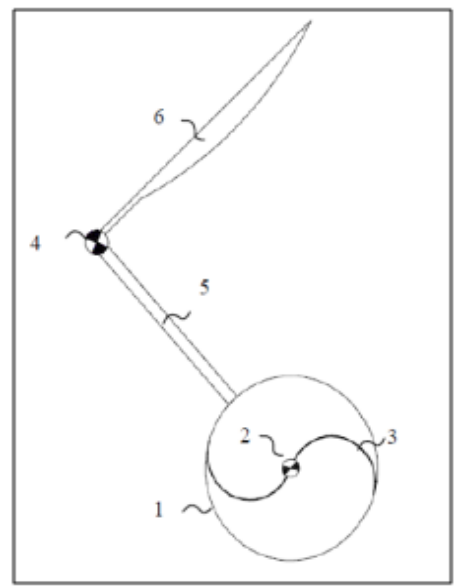

Fig.2. SeaSpoon First Layout

The first simplest layout of the Seaspoon (Fig. 2) consists of a rotor (1) whose spinning axis (2) is submerged at an appropriate depth, considering the sea conditions (wave period, wave height and wavelength), perpendicular to the wave propagation direction. The wave particles, while in motion, hit the rotor blades (3), which start spinning in one direction independently on the wave direction. A connecting rod (5) ties stiffly the rotor axis to a main spinning axis (4). The main spinning axis is placed as well parallel to the rotor axis. It is submerged at an appropriate depth likewise the rotor axis. The main axis is hinged to a flat plate (6), which acts as a rudder for the overall rotation. In turns, the entire device is free to spin around the main axis (4) in the same direction of the propagating waves. At the same time, the blades are set to motion and spins around (2) and (4) at once.

The results of numerical simulations (DiFresco et al. 2015) showed that the Seaspoon (Savonius-type rotor coupled to spoon plate) performs better than a simple Savonius-type rotor, exploiting the peculiarity of the circular velocity field of the flowstream associated to the waves motion. This proves the basic idea on which the Seaspoon is based on. The spoon plate eventually coupled to a rotor with even higher efficiency of the Savonius (e.g. Darrieus-type rotor) can improve its conversion efficiency (DiFresco et al. 2014).

After a first test campaign in a wave flume facility, it was decided to move towards a simple spoon plate and a full-scale prototype (Fig.3) was realized and installed in the gulf of Genova thanks to a elastic beacon installed in open-sea where a complete monitoring campaign is currently in progress. The technical details of the prototype are reported in Tab.1, the most important innovative aspects proposed by the SeaSpoon are its ability of self-orienteering hortogonal to the wave direction, the possibility to move the converter on a vertical direction ( $5 \mathrm{~m}$ ) in order to follow the waves and the fact that the WEC has no visual impact, thanks to the submerged installation. 


\begin{tabular}{|l|c|}
\hline \multicolumn{2}{|c|}{ Technical Sheet } \\
\hline Nominal Power & $1-3 \mathrm{~kW}$ \\
\hline Blades Size & 2 blades $-1 \mathrm{x} 1 \mathrm{~m}$ \\
\hline Nominal Optimized Designed Wave Height & $2 \mathrm{~m}$ \\
\hline Vertical Displacement & $5 \mathrm{~m}$ \\
\hline
\end{tabular}

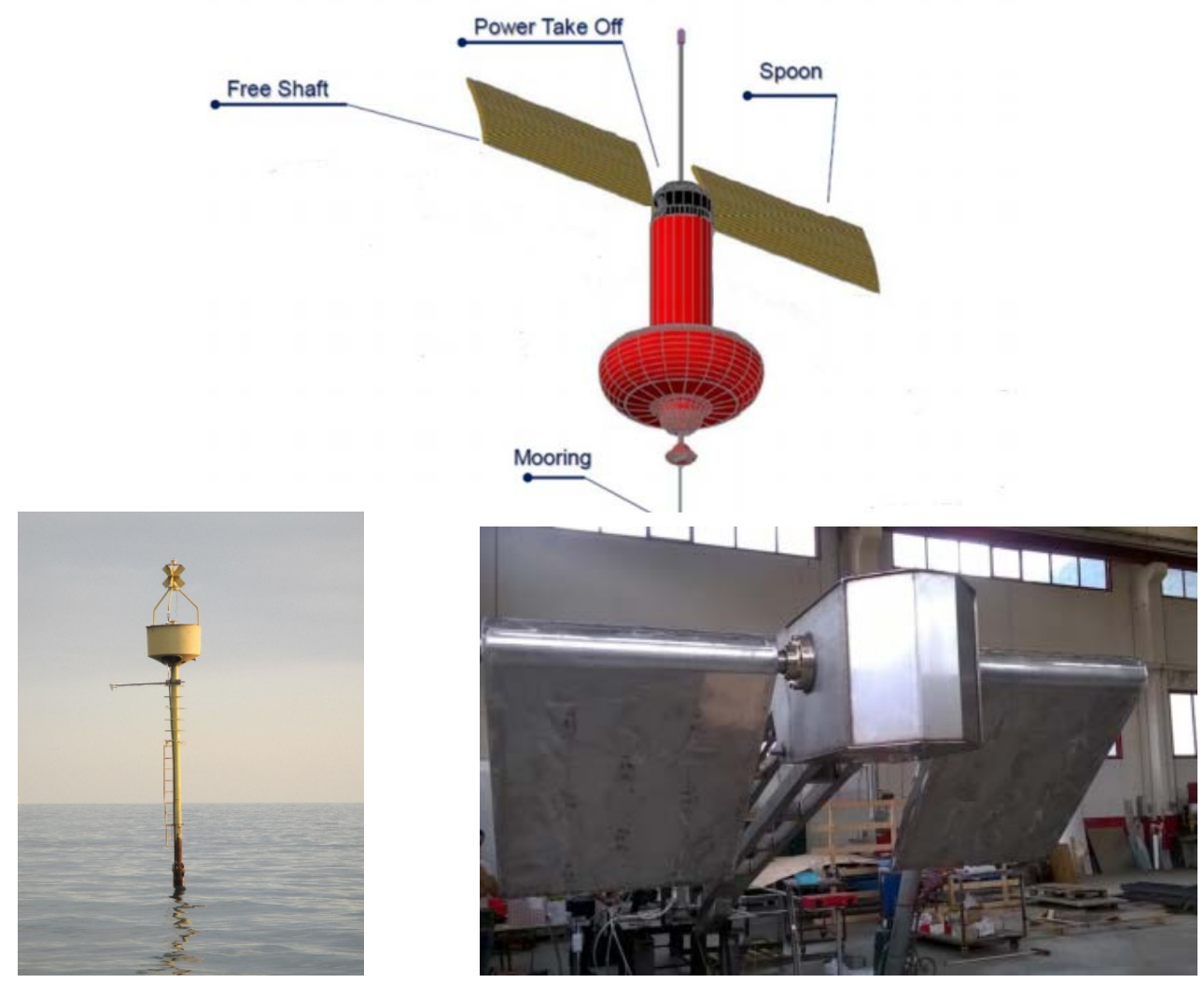

Fig.3. SeaSpoon Full Scale Prototype: Render and Prototype

The monitoring campaign is based on a remote control of the most important parameters where all the data are collected through a MATLAB model (Fig.4):

- Generated power

- Efficency

- Wave height

- Wave period

- Wave-power correlation

- Wave potential

- Daily performance 


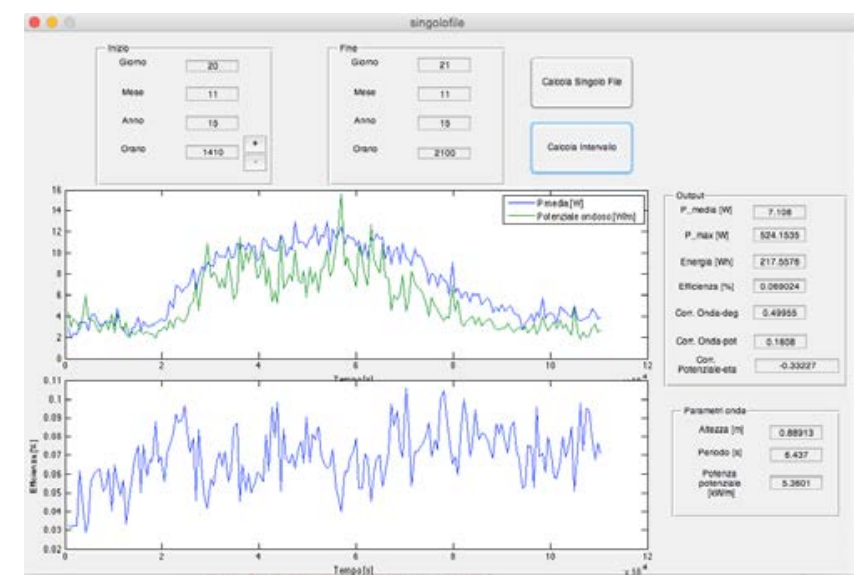

Fig.4. SeaSpoon Monitoring Campaign MATLAB Model

\section{Thermoeconomic Approach and W-ECoMP software}

Thermo-economics aims to find a correlation between the thermodynamics, particularly energy and exergy flows, and the economics of an energy system. The peculiarity of this thermo-economic analysis consists in the use of the concepts of specific consumption of components or processes and the energy costs of the flows; these two items of cost constitute the so-called internal economy of the energy conversion system.

Thermo-economic analysis can be insightful in polygenerative districts, where the energy manager has to decide whether i.e. follow the thermal or electrical demands, and optimise the electricity exchanged with the grid.

The objective of thermo-economics is to indicate where and how energy and money savings are possible and to quantify the results obtained in terms of fuel or money saved.

W-ECoMP (Web-based Economic Cogeneration Modular Program) is an original software tool developed by the Thermochemical Power Group, at the University of Genoa. W-ECoMP aims at the thermo-economic, timedependent analysis and optimization of energy districts: it is characterized by a modular structure that allows the user to easily build complex cycle configurations without significant modifies at the core of the program. This approach maintains the possibility of extending the libraries containing the components (48 modules are available). Each component is described by three subroutines, that define mass and energy flows, off-design performance curves (Ferrari et al. 2014), variable and capital costs. W-ECoMP allows the optimization of energy systems at two different hierarchical levels (Yokohama et al.; Gamou et al.):

- $\quad$ Determination of the best operational strategy for existing energy systems (low level)

- Determination of the optimal size of plant components or whole plant design (high level)

Capital and variable costs are considered for the system size optimization, while only variable costs are considered to optimize the operating strategy of existing energy systems. In the design optimization, the size of each component is evaluated together with its capital cost, through cost functions updated periodically (once a year). The main inputs of the model are: (i) electricity, heating, cooling load curves; (ii) economic scenario where the plant is installed, including trade prices (fuel and energy costs); (iii) component capital costs vs. size; (iv) operating and maintenance costs vs. time; (v) generator off-design performance curves. In particular, offdesign performance curves for the devices installed in the energy district were implemented by the authors in a previous work (Barberis et al. 2016) starting from their real performance measured in experimental tests at different load conditions.

The constraints of the problem are the balance equations between supply and demand of components. For example, as far as the electrical energy balance is concerned, the energy produced by installed prime movers 
(ICE, gas turbines, etc.), the energy sold to the user and the energy consumed by plant components (i.e. compressors, heat pumps) are included in the balance, as follows:

$$
E_{\text {req }}=\sum_{i=1}^{N} E_{i, \text { prod }}+E_{\text {acq }}+E_{\text {virt }}-\sum_{i=1}^{N} E_{i, \text { cons }}
$$

Eq. 1 includes a virtual term as well, representing energy exchanges between the plant and the external environment, necessary to satisfy the optimization constraints (i.e. load demands). The same approach can be applied for thermal and cooling energy balances. W-ECoMP considers only energy and power flows between units: fuel mass flows and consumptions are evaluated from the energy flows and the generators efficiencies. The thermal storage is modelled starting from a volume capacity and evaluating the storable thermal energy by hot water with that volume and a fixed temperature.

At low level, the components size is considered fixed (therefore capital costs are fixed) and a genetic algorithm is used in order to determine the best operational strategy (Barberis et al. 2016). In this case, the software aims to minimize an objective function (Eq. 2) that represents annual variable costs:

$$
C_{\text {var }}=F_{i} \cdot \sum_{i=1}^{N} c_{\text {fuel }, i}+c_{e l} \cdot E_{\text {acq }}+c_{\text {virt }} \cdot\left(F_{\text {virt }}+E_{\text {virt }}+Q_{\text {virt }}^{*}\right)
$$

Variable costs are made up of the following terms: (i) a term related to fuel consumption costs, (ii) a term related to electrical energy costs and (iii) a term that represents "virtual costs". It is important to underline that "virtual flows" represent energy exchanges between the plant and the external environment, necessary to satisfy the optimization constraints (i.e. load demands), as reported in Eq.1. Since these amounts of energy cannot be produced by the plant, penalty costs are associated to virtual flows. Since the term "cvirt" is high (usually, two orders of magnitude higher than the other specific cost terms), the optimization process is forced to find an operational strategy which minimizes virtual flows.

At high level, W-ECoMP is able to perform the size optimization of one or more components at the same time, minimizing the objective function, which includes both variable and fixed annual costs. More details on the high-level optimization are reported in (Barberis et al. 2016). The optimization process is performed by dividing the operational time (usually one year) into a proper number of representative periods, one hour or less depending on the application. At both optimization levels, the constraints of the problems, represented by energy load demands, must be satisfied; if these conditions are not verified, strong penalties are applied and virtual costs associated with virtual flows increase the objective function (Yokohama et al.). Thanks to the presence of the storage, the energy load demands can be managed with more flexibility, allowing for fuel and energy savings as well. For any further detail about the model of the storage implemented in the software, please refer to (Verda et al. 2001).

\subsection{Thermoeconomic Model of the SeaSpoon WEC}

The SeaSpoon Wave Energy Conveerter was modelled in the WECoMP software to be integrated in an already existing model of the Savona Campus SPM, modifying the "Renewable Random Generator" module (Fig.5). This module is able, starting from a "txt file with an hourly profile of the renewable associated potential (solar irradiation, wind speed, wav height and frequency), to calculate the producibility of the Renewable Generator.

In this case the Seaspoon WECoMP was built after a deep statistical analysis of the wave potential of the sea in front of the city of Savona, where it would be installed the Wave Energy Converter. This analysis started from monitored data (weather and meteo open sea floating stations) and from wave forecast models from the Ligurian Sea.

In the analysed scenario, the average wave height is usually between 0 and 3 metres, with rare peaks of 4 or 5 metres. Although the stochastic distribution of these data, some values are often maintained for hours or days around equilibrium values then moving suddenly to set around a new average value of balance. This trend allowed to prepare three average profile of the daily wave potential per each month, related to calm, moderate and wavy situations. These data could be used as input for the "Renewable Random Generator" module. 
Starting from the wave potential equation (Eq.3), it is worthy to consider an average period of the wave to evaluate the producibility of the Wave Energy Converter.

$$
P=\frac{\rho g^{2} H^{2} T}{32 \pi} \quad\left[\frac{W}{m}\right](3)
$$

The values of the periods were identified with a different approach previously described for the wave heigth values and an average value for the three sea conditions were identified that ais equal for all months. These values were directly inserted in the code, and not in the "txt file that the user has to provide to the module for the simulation, so the user, choosing the sea condition (calm, moderate, wavy) impose the period.

According to period and heigth values the three different daily profile were divided as follows:

- Calm, period equal to $5 \mathrm{~s}$ and heigth inferior to $1 \mathrm{~m}$;

- Moderate, heigth between $1 \mathrm{~m}$ and 2,5 $\mathrm{m}$ and period equal to 6,5 s;

- Wavy, heigth higher than 2,5 $\mathrm{m}$ and period equal to 7,5 secondi.

For a complete evaluation of the production of the WEC, the WECoMP software consider a different number of days of the three profile per each month.

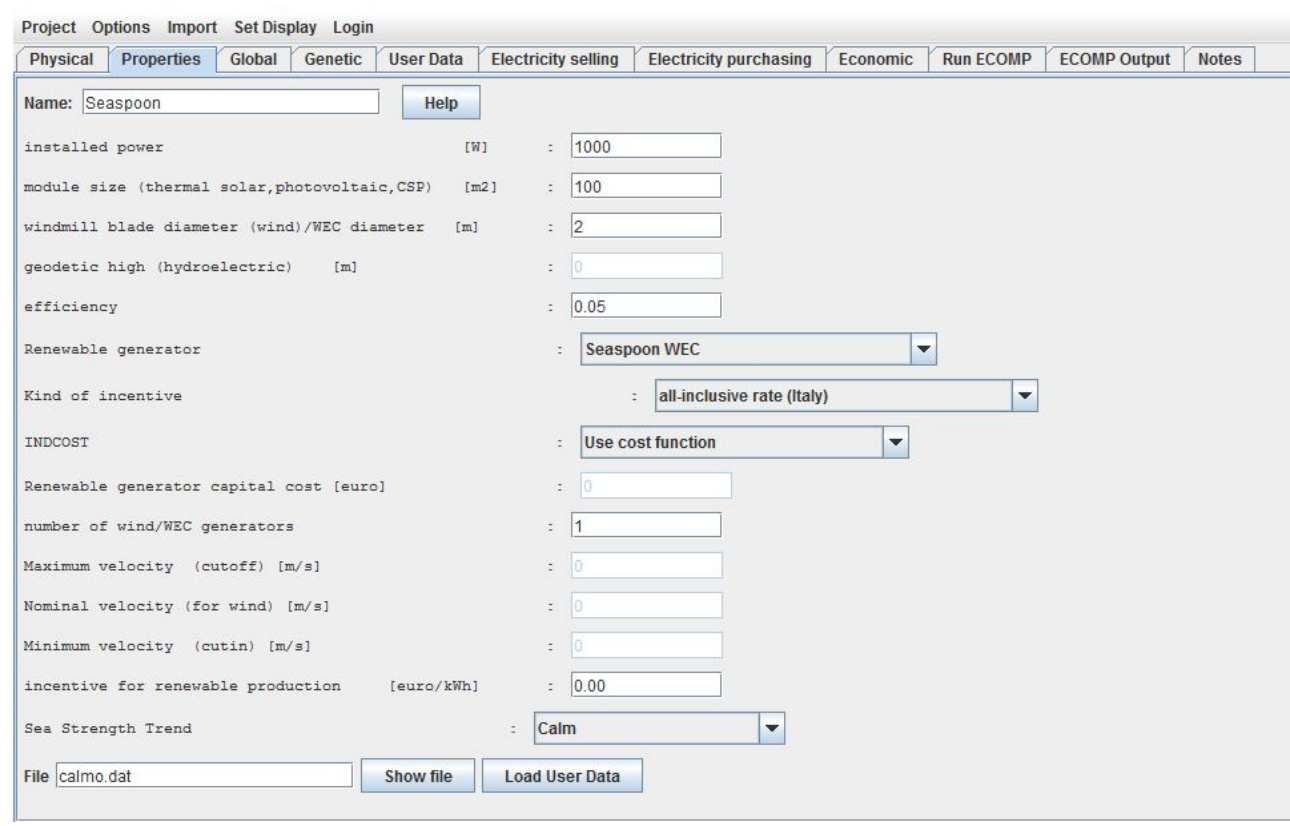

Fig.5. SeaSpoon WECoMP model input data

The input data that has to be inserted by the user together with the *txt file of the wave potential are those one related to the design of the WEC: the size of the blades (strictly related to the portion of the wave front that the generator is able to exploit), the number of WECs present in the farm, the nominal efficiency.

An off-design curve was implemented in the code mostly referred to the ratio between the wave height and the diameter of the blade. This curve was built starting from the producibility data obtained from the open sea monitoring that show how the nominal efficiency is performed by the WEC for a H/D ratio equal to 2. (Fig. 6) This curve has been approximated by two parabolic tendency curve and equations (Eq.4-5): 
- $\quad$ Considering H/D inferior to 2:

$y=0.2981(H / D)^{2}-0.1404 H / D+0.0939(4)$

- Considering H/D superior to 2:

$$
y=0.1514(H / D)^{2}-1.2066 H / D+2.8171(5)
$$

while in order to perform a complete thermoeconomic analysis, a very simplified cost was introduced in the code with a linear cost of $15000 € / \mathrm{Kw}$ that conside all the generation installation, cabling and manufacturing cost.

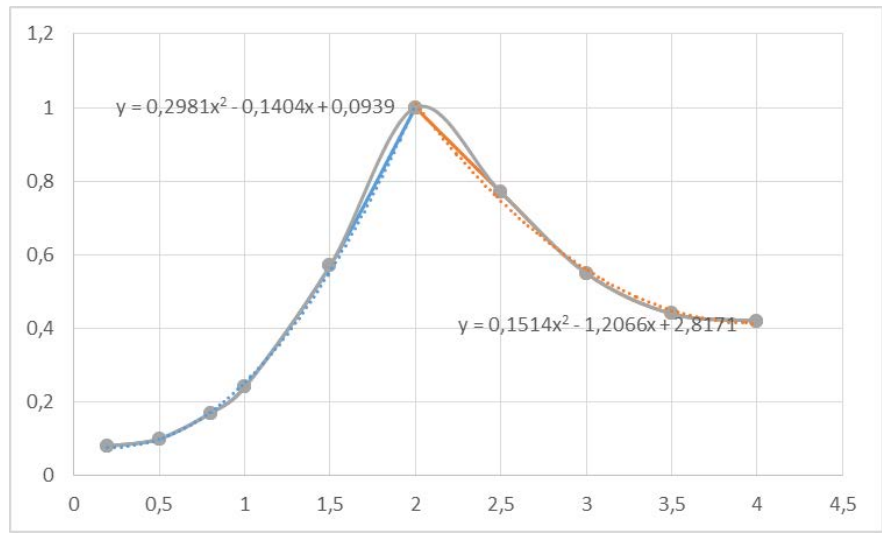

Fig.6. SeaSpoon off-design curve

\subsection{Economic scenario and plant assumptions}

The calculation is performed by dividing the year in 12 representative days (one for each month), for a total of 288 representative periods (hours). Since the campus is closed during the weekend (demands are zero), only weekdays are considered as representative. W-ECoMP software needs several input data, most of them related to the economic scenario where the plant is installed, as follows:

a) Energy load demands: they are one of the optimization problem constraints, they have to be satisfied in all the periods by the traditional and renewable generators installed or purchasing electrical energy from the National grid. The excess of power production of the generators can be also sold to the National grid. A typical electrical and thermal demand load profile is generated for each month from real consumption data received by the SPM controller. Fig. 7 shows the demands for typical winter (continuous lines) and summer (dashed lines) working days.

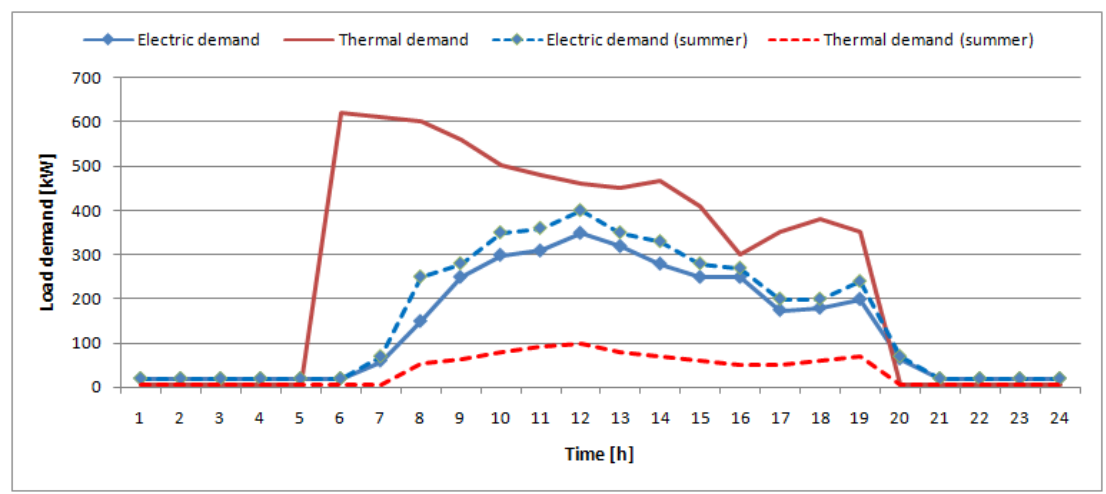

Fig. 8. Electrical / thermal demand profiles in winter (continuous lines) or summer (dashed lines) days 
b) Solar irradiation curves: the irradiation curves considered are related to the city of Savona, located in North Italy. Irradiation hourly average values are calculated hour per hour for each month, as reported in (Barberis et al. 2016).

c) Economic scenario data are presented in Tab.1 according to typical electrical energy and natural gas Italian market prices for energy producers at this power size. The prices of electrical and thermal energy sold to users are referred to the local contract while cooling energy production is considered as an electrical energy saving from the present cooling system (compressor chillers, $\mathrm{COP}=2$ ), therefore cooling power selling price is assumed $0.085 € / \mathrm{kWht}$.

Table 1. Economic Scenario

\begin{tabular}{|l|l|}
\hline Price of natural gas & $0,88 € / \mathrm{kg}$ \\
\hline $\begin{array}{l}\text { Purchasing price of electricity from the } \\
\text { National grid }\end{array}$ & $0,20 € / \mathrm{kWh}$ \\
\hline Selling price of electricity to the National grid & $0,08 € / \mathrm{kWh}$ \\
\hline Selling price of electricity to the users & $0,17 € / \mathrm{kWh}$ \\
\hline Selling price of thermal energy to the users & $0,08 € / \mathrm{kWh}$ \\
\hline Selling price of cooling to the users & $\begin{array}{l}0,085 \\
€ / \mathrm{kWh}\end{array}$ \\
\hline
\end{tabular}

Plant life is assumed equal to 20 years, depreciation time equal to 10 years and inflation rate equal to $3 \%$ [Bejan et al. 1996]. Basing on thermal and electric demand curves, W-ECoMP calculates the best operating strategy.

d) Local Wave Potential Data: as previously introduced the data related to the wave progile in the Savona Gulf were evaluated through a cross-statistical analysis from different monitored and previsions data.

\section{WECoMP Simulation}

In this research the installation of a 10 SeaSpoon farm in the sea shores in front of the city of Savona was considered in order to evaluate how this kind of strong tochastic generators can interact with the Savona Campus SPM. It is worthy to underline that, due to low energy potential of Ligurian Sea, the SeaSpoon contribution in the SPM is significant only during wavy days that are more frequent in winter months like December and February (Fig. 8 - Table 2) 


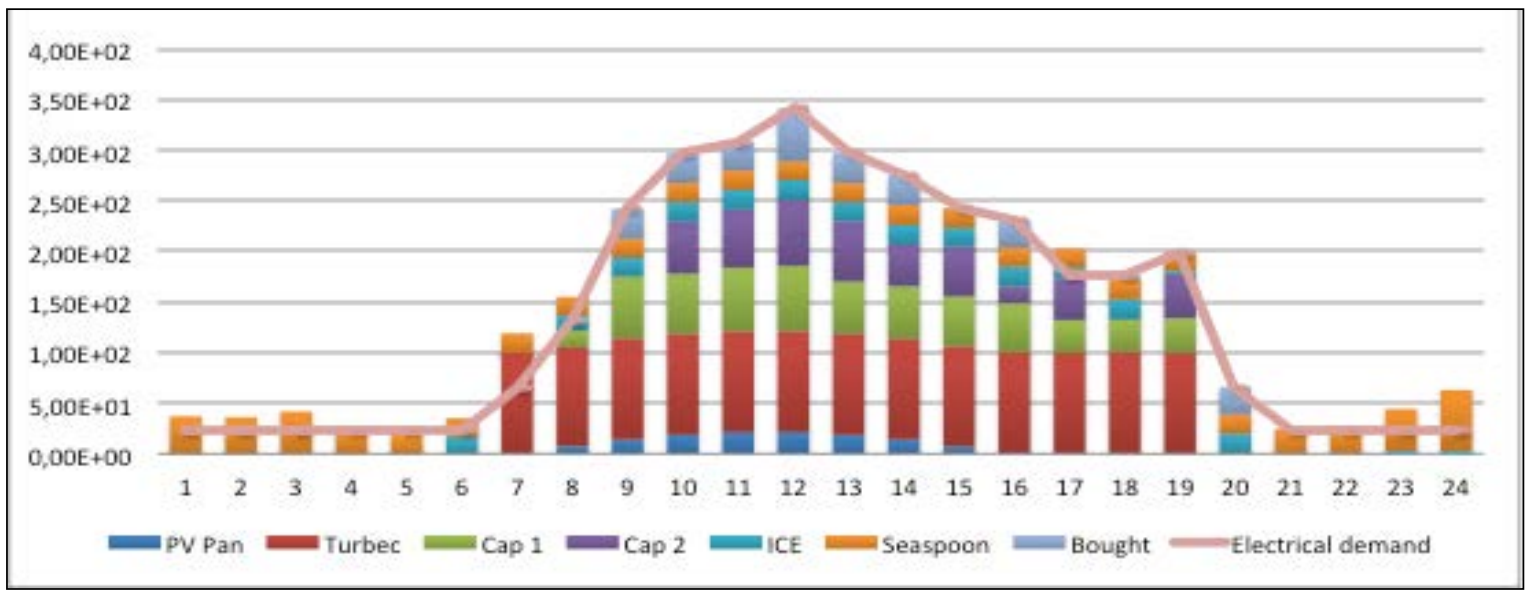

Fig. 8. SPM connected to the SeaSpoon farm - Electrical Management in the month of December

In wavy days a significant contribution of the Seaspoon farm can be observed, with an average power production comparable to that one normally produced by the CHP internal combustion engine TANDEM T20, often even higher. As can be seen from the graphs, the Seaspoon facility is able to statisfy the energy demand of the campus during the night. The exploitation of SeaSpoon energy production at night seems to be plausible as wave presence and profile are fairly predictable. The Seaspoon night overproduction could be sold to the Electrical National grid, or it could be stored in the battery (not the subject of these simulations) for the operations of the peak-shaving during mid-day peaks demand.

Table 2. Yearly Electrical Energy Producibility of a Ten SeaSpoon Farm in Savona Sea [kWh]

\begin{tabular}{|c|c|c|c|c|}
\hline & \multicolumn{4}{|c|}{ Monthly Energy Production [kWh] } \\
\hline & Calm & Moderate & Wavy & Total \\
\hline January & 74,42 & 684,36 & 0,00 & 758,78 \\
\hline February & 64,83 & 510,17 & 427,96 & 1002,95 \\
\hline March & 78,32 & 946,28 & 0,00 & 1024,59 \\
\hline April & 33,02 & 508,94 & 0,00 & 541,96 \\
\hline May & 48,03 & 1121,54 & 0,00 & 1169,57 \\
\hline June & 42,31 & 118,56 & 0,00 & 160,86 \\
\hline July & 13,99 & 101,15 & 0,00 & 115,14 \\
\hline August & 27,44 & 29,44 & 0,00 & 56,88 \\
\hline September & 29,95 & 786,42 & 0,00 & 816,37 \\
\hline October & 44,98 & 431,21 & 471,63 & 947,81 \\
\hline November & 36,32 & 848,06 & 859,84 & 1744,21 \\
\hline December & 22,46 & 409,12 & 1190,89 & 1622,47 \\
\hline \multicolumn{4}{|c|}{ TOTAL [kWh] } & 9961,59 \\
\hline
\end{tabular}

For what it concerns the WECs' contribution during the day, the SeaSpoon production helps to reduce the energey bought from the National grid without any particular negative effect on the management of the thermal demand, entirely satisfied by CHP units particularly at the peak of the electric demand. 
As it can be seen in Table 2, even if the day with a calm sea wave profile are more frequent, the energy production is more or less not remarkable while the wavy days are very few in a year considering the Ligurian Sea in Savona, so despite the good quantity of power produced, SeaSpoon farm doesn't play a significant role in the management of the SPM electric demand.

\section{Conclusions}

In this paper an innovative Wave Energy Converter designed to exploit the wave energy potential of the Mediterranean Sea is presented. The SeaSpoon was briefly introduced, together with the monitoring campaign that is started in Spetember 2015 thanks to the installation of a full scall prototype in the Gulf of Genova. Starting from the first data coming from the experimental campaign, a thermoeconomic model of the SeaSpoon was realized in order to evaluate its connection with an already existing smart polygenerative microgrid and how its stochastic production can influence the management of the energy district.

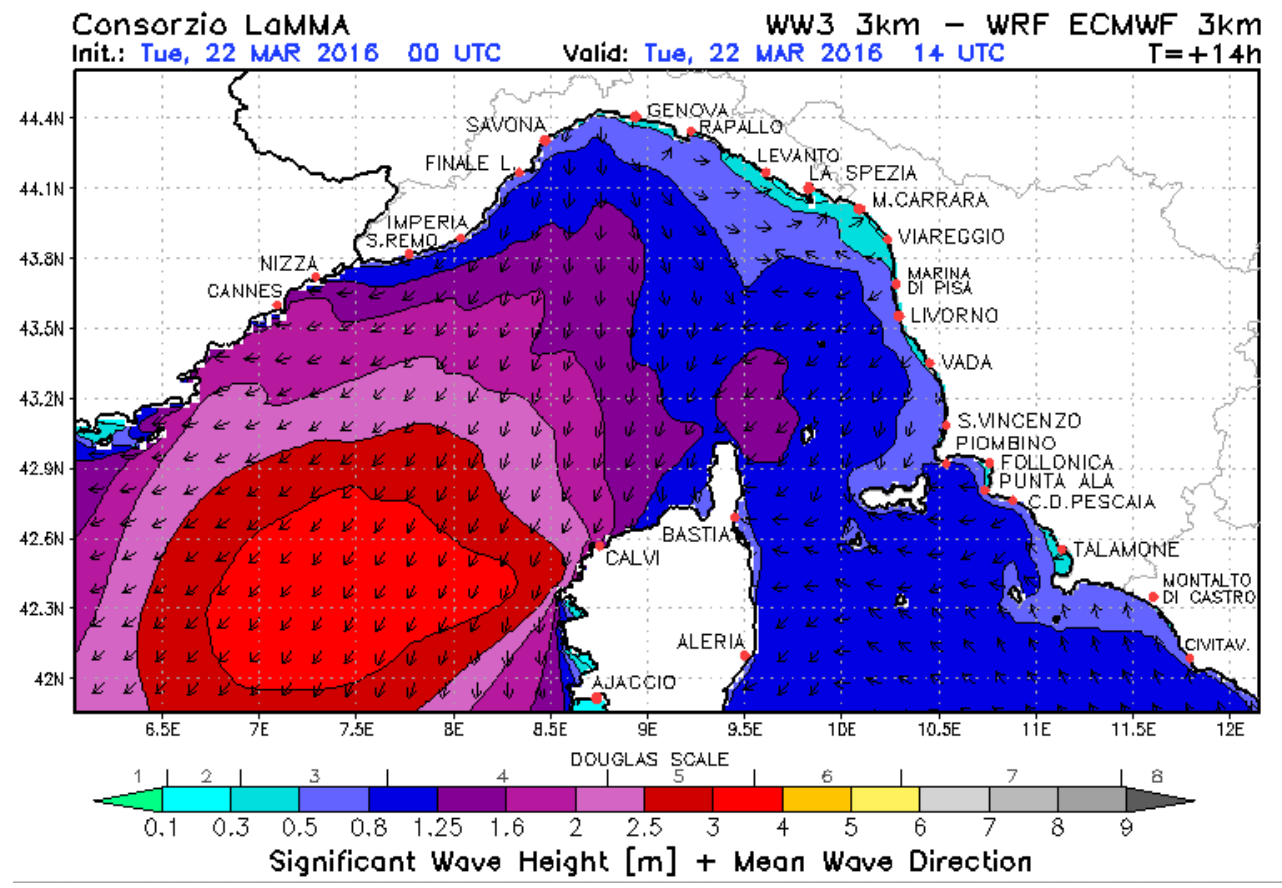

Fig. 9. Example of the wave significant height distribution in the Ligurian Sea

At the end of this analysis performed with the software WECoMP it is possible to say that the interaction of a WEC with a Smart Grid in this kind of scenario (the city of Savona) is almost negligible as the most of the days of the year the energy produced by SeaSpoon is not remarkable due to the calm condition of the sea (Fig.9). Nevertheless it is worthy to underline that, during the rare days of wavy and mderate sea, the contribution of the WEC farm reduce the amount of energy purchased from the electrical National grid.

The energy production is not remarkable because the area considered for the installation, in front of the city of Savona, is characterized by very low waves, less than one meter of significant height for the most of the year. Moreover the off-design performance of the machine strongly reduce the producibility of the machine particularly considering smaller waves. 
In the end, the integration of such this generation in the Savona Campus Smart Polygeneration Microgrid would be possible, as in the 83 days per year with a significant wave potential, it is possible to produces a small share of easily integrable and manageable energy. This integration can not, however, appear very affordable and remunerative due to the reduced production in the designed area. Particularly in summer, when the electrical demand increases and the CHP units production is not remunerative anymore because of the reduced thermal demand and the RES generators production could be acceptable, the Wave Energy converters don't produce a significant amount of energy.

This paper presented the modelling and analysis of the WEC as well as its contribution to the campus SPM. Nevertheless, given the negligible size of the WEC compared to the total size of the SPM it should be expected that one SWEC wouldn't offer an attractive business model regardless of the total production of the WEC. The contribution of WECs for energy district can be interesting for isolated contexts like islands with significant wave potential where this kind of renewable generators can increment the energy independency of the island and the reduction of their use of fossils. In order to develop an attractive exploitation of these generators, it is important to take into account the cost of electrical connection of these open sea units with the shores, reducing as much as possible.

Other possible uses of such this WEC can be searched in renewable stand-alone power generation systems, useful in isolated communities or to recharge AUV vehicles (Autonomous Underwater Vehicle) (Di Fresco et al. 2015) particularly thanks to the submerged installation of the generators.

\section{References}

Barstow, S.; Mork, G.; Mollison, D.; Cruz, J. “The wave energy resource”, in: J. Cruz (Ed.), Ocean Wave Energy, Springer, Berlin, 2008, pp. 93 - 132.

Falnes, J.“A review of wave-energy extraction”, Mar.Struct. 20 (2007), pp.185 - 201.

Olkkonen, Korjonen-Kuusipuro, L.K.; Grönberg, I. “Redefining a stakeholder relation: Finnish energy “prosumers” as co-producers”, Environmental Innovation and Societal Transitions, In Press, Corrected Proof, Available online 8 October 2016, http://dx.doi.org/10.1016/j.eist.2016.10.004

Tvaronavičienè, M.; "Contemporary perceptions of energy security: policy implications”, Journal of Security and Sustainability Issues, 2012, http://dx.doi.org/10.9770/jssi.2012.1.4(1)

Izvercianu, M.; Şeran, S.A.; Branea, A.M. "Prosumer-oriented Value Co-creation Strategies for Tomorrow's Urban Management”, Procedia - Social and Behavioral Sciences, Volume 124, 20 March 2014, Pages 149-156 - http://dx.doi.org/10.1016/j.protcy.2014.10.009

Drew, B.; Plummer, A.R.; Sahinkaya, M. “A review of wave energy converter technology”, Proc. Inst. Mech. Eng., Part A: J. Power Energy, 223 (2009), 887 - 902.

Falcao, A.F. de O. “Wave energy utilization: a review of the technologies”, Renew. Sustain. Energy Rev. 14 (2010), 899 - 918.

Lopez, I.; Andreu, J.; Ceballos, S.; Martinez de Alegria, I.; Kortabarria, I. "Review of wave energy technologies and the necessary power-equipment”, Renew. Sust. Energy Rev. 27, 2013, 413 - 434

Verda, R. V.; Borchiellini, M. Cali “A Thermo-economic Approach for the Analysis of District Heating Systems”, International Journal of Applied Thermodynamics, 4 (2001), 183-190.

Bracco, S.; Delfino, F.; Pampararo, F.; Robba, M.: Rossi, M. “The University of Genoa smart polygeneration microgrid test-bed facility: The overall system, the technologies and the research challenges”, Renewable and Sustainable Energy Reviews, Volume 18, February 2013, Pages 442-459 - http://dx.doi.org/10.1016/j.rser.2012.10.009

Traverso, A.; Fresco, L. Di. Seaspoon: dispositivo per la conversione energetica del moto ondoso del pelo libero di liquidi, Italian patent N.0001405004. 
Fresco, L.Di; Traverso, A.; Barberis, S.; Guglielmino, E.; Garrone, M. “Off-shore wave energy harvesting: a wec-microturbine system “, Oceans’15 Conference Proceedings, April 2015, Genova, Italy.

Fresco, L. Di; Traverso, A. 2014 "Energy conversion of orbital motions in gravitational waves: Simulation and test of the Seaspoon wave energy converter", Energy Conversion and Management, Vol. 86, pp. 1164-1172. http://dx.doi.org/10.1016/j.enconman.2014.06.048

Ferrari, M.L., Traverso, A, Pascenti, M, Massardo, A.F,’Plant management tools tested with a small-scale distributed generation laboratory”, Energy Conversion and Management, 78 (2014) 105-113.

Yokohama R., Ito K., “Optimal design of gas turbine cogeneration plants in consideration of discreteness of equipment capabilities”, Journal of Engineering for Gas Turbines and Power, 128 (2006) 336-343.

Gamou S., Yokohama R., Ito K. ,"Optimal unit sizing of cogeneration systems in consideration of uncertain energy demands as continuous random variables.” Energy Conversion and Management, 43 (2002) 1349-61. - Optimal unit sizing of cogeneration systems in consideration of uncertain energy demands as continuous random variables

Garret Vanderplaats N., "Numerical Optimization Techniques for Engineering Design", McGraw-Hill Pubblishing Company.

Bejan A., Tsatsaronis G., Moran M., 1996, “Thermal design and optimisation”, Interscience Publication, John Wiley \& Sons Inc.

Barberis, S.; Rivarolo, M.; Traverso, A.; Massardo, A.F. “Thermo-economic optimization of a real polygenerative district”, Applied Thermal Engineering (2016), Vol. 97, pp. 1-12, http://dx.doi.org/10.1016/j.applthermaleng.2015.09.012

Cassa Depositi e Prestiti - Studio di Settore (Market Analysis) “Il Mercato del Gas Naturale in Italia: lo sviluppo delle infrastrutture nel contesto europeo” - Italy, March 2013

http://www.mercatoelettrico.org/it/ , last access 1/1/2017.

TurbecSpA, D14127-02 Descrizione Tecnica Ver.2, 2012

asJagen,SpA, Tandem Technical Description, ST_Ver. 3a_13, 2013

Capstone Turbine Corporation. P0410 C30Data Sheet CAP139 | Capstone P/N 331035D,2010

Capstone Turbine Corporation. P0410 C65 \& C65-ICHP Data Sheet CAP139 | Capstone P/N 331035D,2010

http://www.innova.co.it/files/pdf-prodotti/datasheet-trinum-ita_46347.pdf , last access 1/1/2017

http://www.lgvipclub.com.ua/content/files/low_temp_hot_water_driven_absorption_chillers_low.pdf , last access 1/1/2017

https://www.fiamm.com/media/223003/20150209_st523_datasheet.pdf , last access 1/6/2016

LAMMA - Nimbus weather forecast consortium - www.lamma.rete.toscana.it - last access 1/1/2017

ARPAL Meteorological forecast agency - www.arpal.gov.it - last access 1/1/2017

\section{Authors}

Stefano BARBERIS is Associate Researcher at Unversity of Genova. He joined TPG (Thermochemical Power Group www.tpg.unige.it) in 2013 as a PhD student and he is now active in the field of Distributed Generation focusing his interests on energy harvesting , energetic storage (thermal and electric) and Concentrating Solar Power Plants. His main topics are innovative energy cycle thermoeconomics and analysis and optimization of renewable plants and smart grids.

ORCID ID: 0000-0002-6597-8793

Francesco RONCALLO is PhD Student at University of Genova. He obtained his Master Degree in Mechanical Engineering at University of Genoa in 2014 with the Thesis "Sustainable energy solutions in developing countries". He joined TPG as PhD student in 2015. His research is mostly focused on renewable energy and about an innovative renewable energy system based on wave energy conversion, the "Seaspoon". He is also active on cooperative engineering for the sustainable development of emerging countries.

ORCID ID: 0000-0003-4463-6425 
Alberto TRAVERSO is Associate Professor of Energy Systems for Mechanical Engineering. He obtained the Ph.D. in 2004 with the thesis “TRANSEO: A New Simulation Tool for the Transient Analysis of Innovative Energy Systems". His main field of expertise is the time-dependent analysis of energy systems, including fuel cell hybrid cycles. He is also responsible of WTEMP software development for thermoeconomic analysis of innovative energy systems. He is part of the steering committee at TPG for the RollsRoyce Fuel Cell Systems Ltd UTC.

ORCID ID: 0000-0001-5934-3452

Copyright (c) 2016 by author(s) and VsI Entrepreneurship and Sustainability Center

This work is licensed under the Creative Commons Attribution International License (CC BY).

http://creativecommons.org/licenses/by/4.0/

(c) (i) Open Access

